\title{
Research dynamics in Indian fisheries and aquaculture: a scientometric analysis
}

\author{
Nirmal Singh, Surjya Narayan Datta* and Tarvinder Singh Handa
}

The study was carried out to map out the dynamics of scientific output in fisheries and aquaculture in India during the decade 2007-2016, applying scientometric tools. The publication pattern, most productive journals and author have been identified and statistical analysis of citations to publications has been executed. The data was retrieved from 'Scopus' database for phrases such as 'fisheries', 'fishery' and 'aquaculture' as main operators. The search results were filtered for journal articles, English language and for the period 1 January 2007-31 December 2016. The authorship, geographical and keyword landscapes were visualized using free to use visualization software. The study revealed that the number of articles on fisheries and aquaculture have more than doubled from 2007 to 2016. The results indicated a significant correlation between number of citations and number of years from which the article has been published. The United States emerged to be the top most collaborator of India to work in this field followed by South Korea, United Kingdom, Japan and Germany. The network visualization is expected to be useful to the scientific community in analysing the research trends in subject under study and further strengthening the research activities.

Keywords: Aquaculture, fisheries, chronological growth, international collaboration, network visualization, scientometric study.

THE world's population is expected to rise to more than 9 billion by 2050 eliciting $70 \%$ increase in global demand for food, feed and fibre. Moreover, rapid changes are expected in the life style and consumption patterns due to growing urbanization resulting in the decline in shares of grains and pulses and huge increase in the consumption of vegetables, fruits, meat, dairy and fish ${ }^{1}$. This formidable challenge will give rise to alarming situations particularly in developing countries where people still suffer from poverty and hunger ${ }^{2}$. In such a scenario, fisheries and aquaculture are expected to play a vivacious role in providing nutritional security to the food basket ${ }^{3}$.

Fish is an important part of the human diet and provides about $20 \%$ of animal protein intake, globally ${ }^{4}$. On one hand, it serves as a healthy food for the affluent world owing to its oil rich in polyunsaturated fatty acids (PUFAs) and on the other hand, fish is a health food owing to its proteins, oils, vitamins and minerals and other benefits associated with the consumption of small indigenous fishes by the people in the other extreme of

\footnotetext{
Nirmal Singh is in the University Library, Guru Angad Dev Veterinary and Animal Sciences University, Ludhiana 141004, India, Surjya Narayan Datta is in the Department of Fisheries Resource Management, College of Fisheries, Guru Angad Dev Veterinary and Animal Sciences University, Ludhiana 141004 , India and Singh Handa is in the Indian Institute of Technology Ropar, Nangal Road, Rupnagar 140 001, India. *For correspondence. (e-mail: surjya30740@gmail.com)
}

the nutrition scale ${ }^{5}$. Fisheries and aquaculture contribute significantly to food security and livelihoods. Fish provides essential nutrition for nearly 3 billion people and at least $50 \%$ of animal protein and minerals to 400 million people from the poorest countries. Over 500 million people in developing countries depend, directly or indirectly, on fisheries and aquaculture for their livelihoods. Aquaculture is the world's fastest growing food production system, growing at the rate of $7 \%$ annually and fish products are among the most widely traded food, with more than $37 \%$ (by volume) of world production traded internationally.

In India too fisheries sector occupies an important place in the socio-economic development of the country. It has been recognized as a major income and employment generator as it stimulates growth of a number of subsidiary industries, and is a source of cheap and nutritious food besides being a foreign exchange earner. Most importantly, it is the source of livelihood for a large section of economically backward population of the country. The fisheries' resources of the country comprise both marine (exclusive economic zone (EEZ) of 2.02 million sq. $\mathrm{km}$, a continental shelf area of $530,000 \mathrm{sq} . \mathrm{km}$ and a coast line of $8118 \mathrm{~km})$ and inland $(45,000 \mathrm{~km}$ of rivers, $3.0 \mathrm{~m}$ ha of reservoirs). The export of 1.05 million tonnes fish and fish products worth Rs 3344.2 million constituting $10 \%$ of total exports of the country and $20 \%$ of the agricultural exports, make it the largest agricultural 
sub-sector ${ }^{6}$. Constituting about $6.3 \%$ of the global fish production, the sector contributes to $1.1 \%$ of the GDP and $5.15 \%$ of the agricultural GDP. The total fish production of 10.07 million metric tonnes presently has nearly $65 \%$ contribution from the inland sector and nearly the same from culture fisheries. Paradigm shifts in terms of increasing contributions from inland sector and further from aquaculture are significant over the years. With high growth rates, the different facets of marine fisheries, coastal aquaculture, inland fisheries, freshwater aquaculture, cold water fisheries influence the food, health, economy, exports, employment and tourism of the country. India is the third largest producer of fisheries and second of aquaculture with 50 different types of fish and shellfish products being exported to 75 countries around the globe, and this sector provides employment to nearly 14 million people ${ }^{6}$. Fisheries have been recognized as dominant income and employment generators especially for a large section of economically underprivileged population of the nation ${ }^{7}$. However, assessment of fishery resources and their potential in terms of fish production, operations and landing and berthing facilities for fishing vessels, improving welfare of the fishermen, etc. are some of the challenges faced by this agricultural sub-sector.

Sustained research efforts are crucial for the growth and development of fisheries and aquaculture and the availability of literature on the subject is essential for further research and scientific developments to confront new challenges and issues. Hence, a quantitative assessment of the literary output on fisheries and aquaculture can provide an understanding of the research trends in the subject. Bibliometric analysis allows mapping and generating knowledge management indicators in information communication systems providing an outline of the literary outcomes in a given subject ${ }^{8}$. In science and technology domain, the term 'scientometrics' is used more preferably. Bibliometric/scientometric studies provide an outline of the literary outcome in a given subject over a selected period and are also useful to academic institutions for collecting and organizing information resources of their interest.

The scientometric study in Indian fisheries and aquaculture sector with respect to chronological growth, citation pattern of the articles, international collaboration and subject visualization has not been carried out yet and thus this study can be of paramount significance in this sector.

\section{Review of status of research and development in the subject}

Several studies have been conducted to examine the pattern of scientific literature on various subjects including neuroscience, zika virus, diarrhoea, malaria, climate change, etc. A comprehensive study analysing the Indian literary output on fisheries and aquaculture still needs to be conducted. However, in some of the other countries, sincere efforts have been made on the scientometric analysis of literature in fisheries and aquaculture like, Dias et $a l .{ }^{9}$ did an analysis on net cages in order to determine the environmental issues, using Thomson Reuters database (ISI Web of Knowledge), with 'cage culture' and 'net cage' as keywords; Sylvain ${ }^{10}$ conducted a bibliometric analysis to reveal the key features of Canadian research in aquaculture. The relevance of bibliometric aspects for science policy-making was also emphasized; Santos and Vianna ${ }^{11}$ performed a scientometric analysis for 12 species of Cynoscion from the Western Atlantic to explore the evolution of knowledge and the topics covered between 1945 and 2015; Aksnes and Browman ${ }^{12}$ studied the bibliometric indicators to characterize recent research activity in fisheries science with the objective of garnering insights into the execution of such increased efforts; Natale et al. ${ }^{13}$ examined the literature on aquaculture published between 2000 and 2011 using bibliometric and computational semantics. The results revealed that the broad themes of research on aquaculture were related to genetics and reproduction, growth and physiology, farming systems and environment, nutrition and water quality and health. 'Aquaculture', 'Aquaculture Research' and the Journal of World Aquaculture Society were found to be the major sources of articles. Alves and Minte-Vera ${ }^{14}$ conducted a broad and comprehensive analysis of the approaches and limitations of Brazilian fresh water fisheries research studies through scientometric analysis. The findings revealed that after 2008, the creation of Ministry of Fisheries and Aquaculture, which indicated the fallacy of disregarding scientific knowledge, could be permeating decision making agencies.

At the national level, few attempts have been made to assess the scientific productivity on fisheries and aquaculture literature published in specific journals including the European Journal of Phycology ${ }^{15}$ and Aquaculture ${ }^{16}$. Jayashree and Arunachalam ${ }^{17}$ and Arunachalam and Jayashree $^{18}$ conducted scientometric studies on fish research in India and comparison of fish science research of China and India respectively. These studies were conducted nearly two decades back and since that the research dynamics have changed profoundly in almost every subject. Hence, an exhaustive study covering scientific literature published in recent years is the need of the hour. Rana and Agarwal ${ }^{19}$ conducted a study to examine the authorship and collaborative research patterns in Indian wildlife and fisheries based on the data collected from 'Wildlife Review and Fish Review' published between 1980 and 1989. Similarly, an investigation was made on the authorship pattern in Aquaculture Journals, based on the data collected from Aquatic Sciences and Fisheries Abstracts for the period 1991-2001 (ref. 20). However, this study was limited to assess the authorship pattern and collaboration only. In another bibliometric study of research productivity on fish and fishing 
industry in India ${ }^{21}$, again only a few aspects of literature were examined. The authorship and international collaborations remained out of the scope of this study. Another study explored the scientometric aspects of 1373 articles indexed in Web of Science database published during 2011-2016 (ref. 22). The number of articles included in this study represented only a fraction of articles published in mainstream journals. This also excluded articles on aquaculture.

An exhaustive attempt to analyse the various scientometric aspects of literature on fisheries and aquaculture of India is still needed. No attempt has been made for network visualization of literary outcome of the country in this sector.

\section{Objectives of the study}

The main objectives of the study are: (1) To analyse the chronological growth and citation pattern of scientific productivity in fisheries and aquaculture research in India during 2007-2016. (2) To visualize the research collaboration at international level. (3) To visualize the subject maps and authorship collaboration networks.

\section{Materials and methods}

The study was conducted at Guru Angad Dev Veterinary and Animal Sciences University (GADVASU), Ludhiana, India. Data was accessed from 'Scopus' database during July 2017 to accomplish the objectives of the study. An advanced search was conducted in the database using the phrases 'fishery', 'fisheries' and 'aquaculture'. The Boolean operator 'OR' was applied to get exhaustive results represented by either of these phrases. The search was filtered for occurrence of phrase terms in the title, abstract and keywords of articles. The results were further filtered for English language, journal articles for the period 1 January 2007-31 December 2016 and the country India. The string search retrieved 11,012 results. The data was downloaded. After deleting 13 irrelevant records, 10,999 articles were found relevant for analysis. Data analysis was performed on these 10,999 relevant results using frequencies and mean values. The publishing trends of articles on the subject under study, citations to publications, most productive journals and authors were illustrated. The geographical collaboration (international), subject terms and authorship collaboration visualization maps were developed using visualization software.

\section{Results and discussion}

The various facets of scientific output on fisheries and aquaculture including its growth, authorship collaboration, publication pattern, international collaboration, etc. are analysed and discussed in the following sections.

\section{Chronological growth}

Year-wise productivity of articles is represented in Table 1. The results revealed that the number of articles on fisheries and aquaculture have more than doubled from 2007 to 2016. During 2007 there were 614 articles on the subject, which increased almost continuously (except for the year 2015) to reach the figure of 1456 during 2016. This shows that the research efforts in fisheries and aquaculture are steadily increasing over the years during the last decade.

\section{Citation pattern of the articles}

The citations to an article are accepted as one of its quality indicators. Articles are expected to get more citations over the period. The citation trend of articles in a chronological order is tabulated in Table 2. It is evident from Table 2 that the articles published during 2016 have least number of citations and articles published during 2010 earned highest number of citations. Except this, the total number of citations for articles for each year decreased continuously from 2007 to 2016. Likewise, the average number of citations to articles also decreased (except year 2012), earning 15.87 citations during 2007 to 1.17 citations during 2016.

\begin{tabular}{lcc}
$\begin{array}{c}\text { Table 1. } \\
\text { fisheries and aquaculture sector during }\end{array}$ & $\begin{array}{c}\text { Year-wise } \\
\text { andicles }\end{array}$ & in \\
Year & No. of articles & Percentage \\
\hline 2007 & 614 & 5.58 \\
2008 & 630 & 5.73 \\
2009 & 842 & 7.66 \\
2010 & 955 & 8.68 \\
2011 & 1060 & 9.64 \\
2012 & 1286 & 11.69 \\
2013 & 1316 & 11.96 \\
2014 & 1452 & 13.20 \\
2015 & 1388 & 12.62 \\
2016 & 1456 & 13.24 \\
\hline
\end{tabular}

Table 2. Citation pattern of articles

\begin{tabular}{lrrc}
\hline Year & Citation & Articles & $\begin{array}{c}\text { Average citation } \\
\text { per article }\end{array}$ \\
\hline 2007 & 9749 & 614 & 15.88 \\
2008 & 9346 & 630 & 14.83 \\
2009 & 8937 & 842 & 10.61 \\
2010 & 12,511 & 955 & 13.10 \\
2011 & 8730 & 1060 & 8.23 \\
2012 & 7618 & 1286 & 5.92 \\
2013 & 7159 & 1316 & 5.43 \\
2014 & 5791 & 1452 & 3.99 \\
2015 & 3469 & 1388 & 2.50 \\
2016 & 1704 & 1456 & 1.18 \\
Total & 75,014 & 10,999 & 6.82 \\
\hline
\end{tabular}




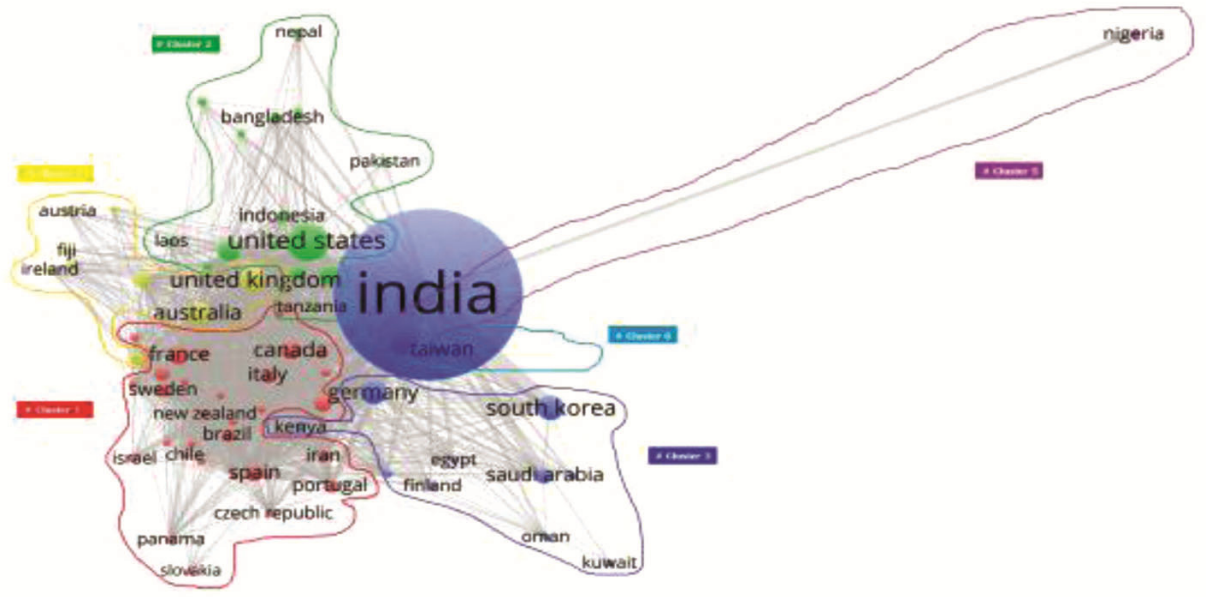

Figure 1. International collaboration map.

The correlation coefficient was calculated to statistically examine the relation between number of citations and age of the articles. The results revealed a significant correlation at 0.01 level $(r=-0.207)$, between the number of citations and number of years from which the articles are published, making it obvious that the number of citations to an article are likely to increase over years.

\section{International collaboration}

The geographical location of authors represents the contribution of countries towards literature on the subject. Authors from 130 countries contributed to articles on fisheries and aquaculture in collaboration with authors from India. The network visualization of 68 countries which contributed five or more articles in collaboration with India is given in Figure 1. The VOSviewer assigns the nodes in a network to clusters by default. A cluster contains nodes that are closely related to each other and each node in a network fall under one cluster only ${ }^{23}$. The collaboration visualization map comprises nodes and links. The links between two countries reveal that the researchers from these nations have co-authored at least five papers on fisheries and aquaculture. The thickness of links represents the frequency of co-authorship collaboration between nations and size of the nodes reveals the strength of collaboration with India in terms of number of articles.

The international collaboration on fisheries and aquaculture is visualized based on the cluster method using VOS viewer. Each cluster is labelled with a circle in a different colour and tagged with cluster number. Based on the cluster approach provided by VOSviewer, the geographical visualization comprised of six clusters based on the close proximity of the countries.

The United States emerged as the top most collaborator of India to work on fisheries and aquaculture followed by
South Korea, United Kingdom, Japan and Germany. Countries like Australia, China, Malaysia, Canada and France are also among the top 10 collaborators of India. The clusters of countries based on their close proximity of collaboration are listed below:

Cluster 1: Argentina, Belgium, Brazil, Cameroon, Canada, Chile, Colombia, Czech Republic, Denmark, Ecuador, France, Greece, Hong Kong, Iran, Israel, Italy, Madagascar, Mexico, New Zealand, Panama, Portugal, Puerto Rico, Russian Federation, Slovakia, South Africa, Spain, Sri Lanka, Sweden, Switzerland, Turkey, United Arab Emirates.

Cluster 2: Bangladesh, Cambodia, China, Hungary, Indonesia, Laos, Malaysia, Nepal, Pakistan, Philippines, Singapore, Tanzania, Thailand, United States, Viet Nam.

Cluster 3: Egypt, Ethiopia, Finland, Germany, India, Kenya, Kuwait, Oman, Poland, Saudi Arabia, South Korea.

Cluster 4: Australia, Austria, Fiji, Ghana, Ireland, Mozambique, the Netherlands, Norway, United Kingdom.

Cluster 5: Japan, Nigeria.

Cluster 6: Taiwan.

\section{Subject visualization}

The subject visualization was illustrated on the basis of author keywords. The visualization map based on 133 author keywords (out of total 23,046) having more than 30 occurrences in articles, is illustrated in Figure 2. Based on the cluster approach of VOSviewer, the eight clusters given below, were developed according to the close proximity of author keywords:

Cluster 1: Abundance, Arabian Sea, bacteria, Bay of Bengal, biodiversity, chlorophyll, climate change, conservation, cyanobacteria, distribution, diversity, estuary, eutrophication, Gulf of Mannar, heavy metals, India, mangrove, mangroves, nutrients, phylogeny, 


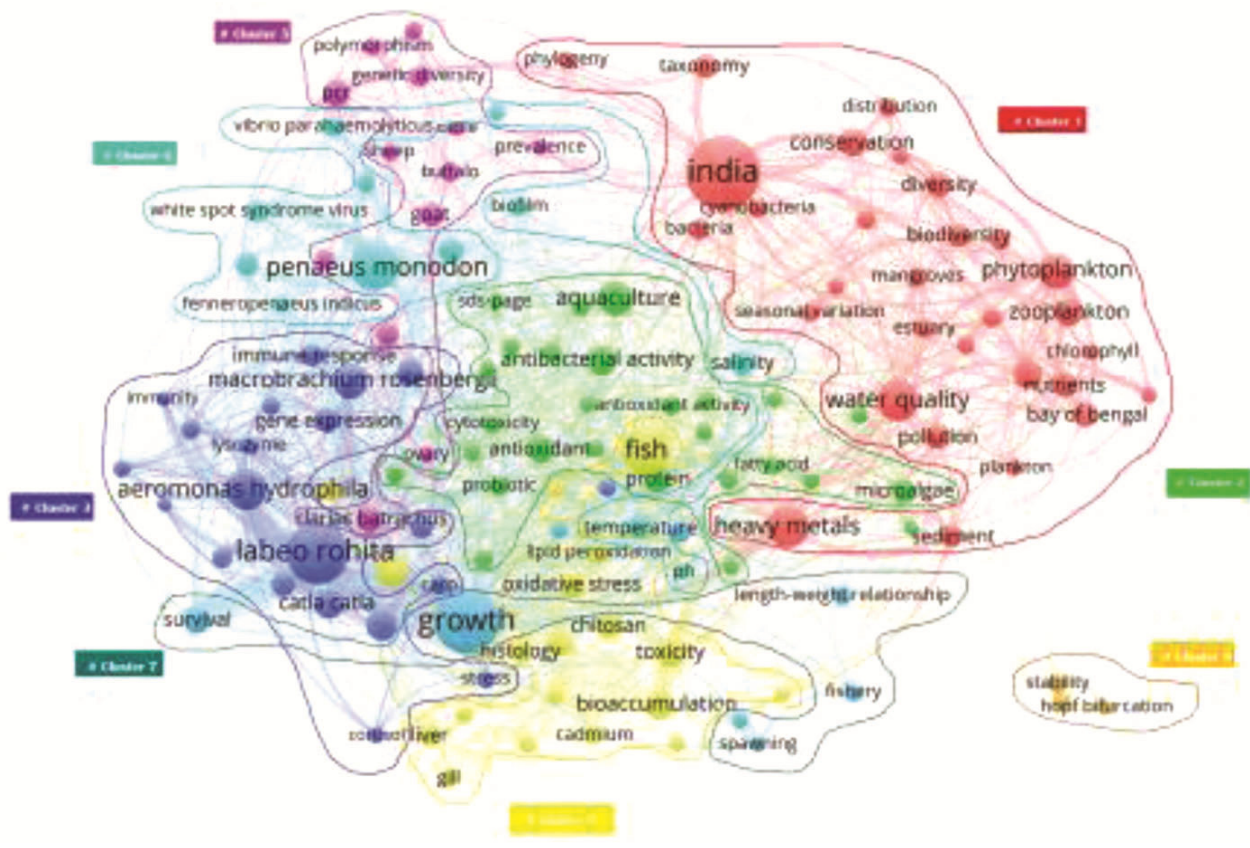

Figure 2. Subject visualization.

physico-chemical parameters, phytoplankton, plankton, pollution, principal component analysis, seasonal variation, sediments, taxonomy, water quality, zooplankton.

Cluster 2: Antibacterial, antibacterial activity, antimicrobial activity, antioxidant, antioxidant activity, aquaculture, biodiesel, biomarker, biomass, Channa striatus, characterization, cytotoxicity, fatty acid, fatty acids, fermentation, genotoxicity, hematology, lipid, microalgae, probiotic, protein, proximate composition, response surface methodology, Scylla serrate, sds-page, seaweed, sem.

Cluster 3: aeromonas, hydrophila, carp, Catla catla, Cirrhinus mrigala, cortisol, Cyprinus carpio, disease resistance, gene expression, growth performance, immune response, immunity, immunostimulant, Indian major carps, innate immunity, Labeo rohita, lysozyme, Macrobrachium rosenbergii, probiotics, rohu, stress.

Cluster 4: Adsorption, antioxidants, bioaccumulation, cadmium, Channa punctatus, chitosan, copper, fish, gill, haematology, heavy metal, Heteropneustes fossilis, histology, histopathology, lipid peroxidation, liver, oreochromis mossambicus, oxidative stress, toxicity.

Cluster 5: Buffalo, catfish, cattle, Clarias batrachus, elisa, biodiversity, goat, ovary, pcr, polymorphism, prevalence, rapd, sheep.

Cluster 6: Antibiotic resistance, biofilm, Fenneropenaeus indicus, Penaeus monodon, ph, salinity, shrimp, temperature, Vibrio harveyi, Vibrio parahaemolyticus, white spot syndrome virus, wssv.

Cluster 7: Fecundity, fishery, growth, Lates calcarifer, length-weight relations, mortality, spawning, survival.

Cluster 8: Harvesting, hopf bifurcation, biodiversity.
A careful observation of visualization map revealed that the subjects of oceanography/hydrobiology, fish microbiology and health, fish nutrition, fish haematology, carcass composition, fish growth, immunity and immune-stimulants, aquatic environment health and biodiversity and integrated system have been of major interest among researchers/scientists working on fisheries and aquaculture. Research has also been conducted on some of the major food fish including Indian major carps (Catla catla, Cirrhinus mrigala, Labeo rohita); Lates calcarifer, Channa punctatus and catfish species like Clarias batrachus. Besides this farming of fresh water prawn Macrobrachium rosenbergii and shrimp Fenneropenaeus indicus, Penaeus monodon also gained attention of the researchers. Some aspects of disease diagnosis and causative agents like Vibrio harveyi, Vibrio parahaemolyticus, white spot syndrome virus were under top priority among the researchers.

\section{Authorship collaboration network}

A total of 20,236 authors contributed to 10,999 articles. An author visualization map of 209 authors with contributions to more than 20 articles is given in Figure 3. R. Kumar, S. Kumar, A. Kumar, W. S. Lakra and A. K. Pal emerged to be the most productive authors having contributed to more than 100 articles each. Since authors represent respective institutions, an attempt was made to analyse the instuitional collaborations based on authorship collaborations.

The intra- and inter-institutional collaboration networks based on authorship collaboration clusters illustrated in Figure 3 are given below: 


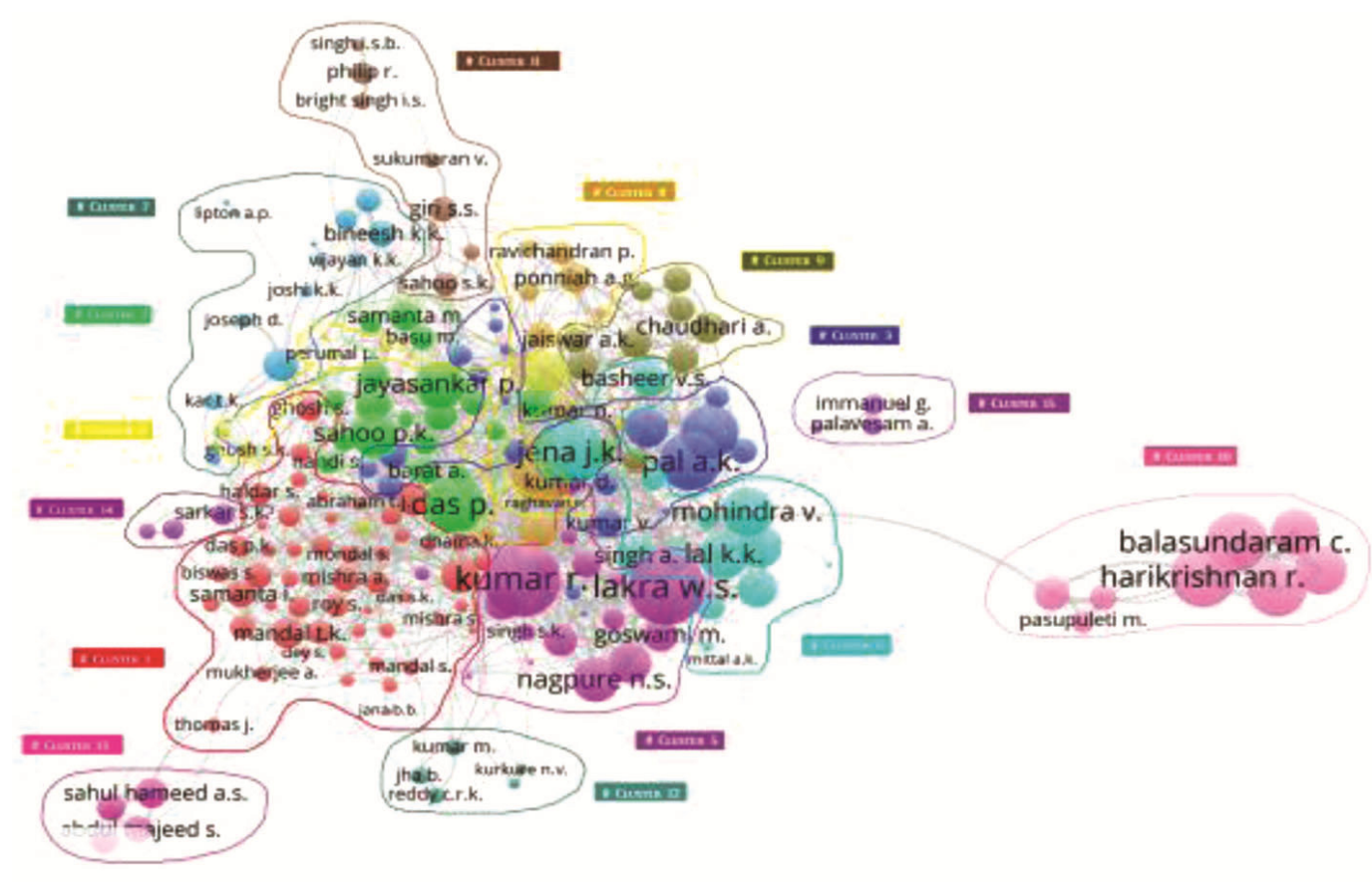

Figure 3. Authorship collaborations.

Cluster 1: It represents the collaborations between authors from Utkal University, Bhubaneswar; KIIT University, Bhubaneswar; Jadavpur University, Kolkata; Indian Institute of Technology, Kharagpur; Ultra-tech, Environmental Consultancy and Laboratory, Pune; Central Inland Fisheries Research Institute, Barrackpore, Kolkata; West Bengal University of Animal and Fishery Sciences, Kolkata; Central Glass and Ceramic Research Institute, Kolkata; University of Calcutta, Kolkata; Network for Fish Quality Management and Sustainable Fishing, Ernakulam, India; National Research Centre on Yak, Arunachal Pradesh; Central Salt and Marine Chemicals Research Institute, Bhavnagar; Central Institute of Freshwater Aquaculture, Kausalyaganga, Bhubaneswar; Indian Institute of Water Management, Bhubaneswar; Institute of Agriculture, Sriniketan, West Bengal; Central Agricultural University Lembucherra, Tripura, Indian Veterinary Research Institute, Izatnagar; Indian Statistical Institute, Kolkata; Uttarbanga Krishi Viswavidyalaya, Majhian, West Bengal; University of Burdwan, Burdwan, West Bengal.

Cluster 2: This cluster shows authors' collaboration from the Directorate of Coldwater Fisheries Research, Bhimtal; Central Institute of Freshwater Aquaculture, Bhubaneswar; National Bureau of Fish Genetic Resources, Lucknow; Central Institute of Fisheries Education, Mumbai and West Bengal; University of Animal and Fishery Sciences, Kolkata.

Cluster 3: Cluster 3 shows the collaborative efforts from the Central Institute of Fisheries Education, Mumbai; Central Inland Fisheries Research Institute, Barrack- pore, Kolkata; Directorate of Coldwater Fisheries Research, Bhimtal; Central Institute of Fisheries Technology, Cochin; Ghent University, Belgium; West Bengal University of Animal and Fishery Sciences, Kolkata; University of Delhi, Delhi; Indian Institute of Agricultural Biotechnology, Ranchi; University of Kashmir, Srinagar.

Cluster 4: It represents authorship collaboration of the Annamalai University, Tamil Nadu; Zoological Survey of India, Kolkata; University of Burdwan, Golapbag Burdwan, West Bengal; National Research Centre on Mithun, Jharnapani, Nagaland; Indian Veterinary Research Institute, Izatnagar; Central Marine Fisheries Research Institute, Kochi, Kerala; St. Xavier's College (Autonomous), Palayamkottai; Nitte University, Mangalore; Kerala University of Fisheries and Ocean Studies, Kochi, Kerala; Central Institute of Fisheries Education, Mumbai; Bharathiar University, Coimbatore, Tamil Nadu; Anna University Campus, Chennai, Tamil Nadu; Bharathidasan University, Tiruchirappalli, Tamil Nadu.

Cluster 5: This shows the collaborative trend among authors from the National Bureau of Fish Genetic Resources, Lucknow; Veer Kunwar Singh University, Bihar; Wildlife Institute of India, Dehradun, Uttarakhand; Central Institute of Fisheries Education, Versova, Mumbai; National Institute for Interdisciplinary Science and Technology, Trivandrum; North East Institute of Science and Technology, Jorhat; Academy of Scientific and Innovative Research, New Delhi; Central Agricultural University, Lembucherra, Tripura; National Dairy Research Institute, Karnal; Indian Institute of Petroleum, Dehradun, 
Uttarakhand; Govind Ballabh Pant University of Agriculture and Technology, Pantnagar; University of Delhi, Delhi and Alagappa University, Tamil Nadu.

Cluster 6: Cluster 6 depicts the collaborative efforts among the Central Marine Fisheries Research Institute, Kochi, Kerala; Assam Agriculture University, Assam; Assam University, Silchar, Assam; National Bureau of Fish Genetic Resources, Lucknow; Banaras Hindu University, Varanasi; Indian Institute of Toxicology Research, Lucknow and Annamalai University, Tamil Nadu.

Cluster 7: It represents collaboration among the Central Marine Fisheries Research Institute, Kochi, Kerala; National Institute of Food Technology Entrepreneurship and Management, Kundli, Haryana; Indian Institute of Engineering Science and Technology, Shibpur, West Bengal and Pondicherry University, Puducherry.

Cluster 8: It shows the collaborative trends among authors from the Central Institute of Brackishwater Aquaculture, Chennai; Aligarh Muslim University, Aligarh, Uttar Pradesh; National Institute of Abiotic Stress Management, Malegaon; Madras Research Centre of Central Marine Fisheries Research Institute, Chennai; Central Institute of Freshwater Aquaculture, Kausalyaganga, Orissa.

Cluster 9: This cluster is based on the intra- or interdepartmental collaboration among authors from the Central Institute of Fisheries Education, Versova, Mumbai.

Cluster 10: It is based on the collaboration among the SRM University, Kattankulathur, Chennai; Tamil University, Thanjavur, Tamil Nadu; Pachaiyappa's College for Men, Kanchipuram, Tamil Nadu; Jeju National University, South Korea; Thanthai Hans Roever College, Perambalur; Central Drug Research Institute, Lucknow.

Cluster 11: This cluster is drawn on the basis of collaborations among authors from the Cochin University of Science and Technology, Kochi, Kerala; Directorate of Coldwater Fisheries Research, Champawat; Seoul National University, South Korea; Central Institute of Freshwater Aquaculture, Kausalyaganga, Odisha; Periyar Maniammai University, Thanjavur, Tamil Nadu.

Cluster 12: Cluster 12 depicts the joint efforts of the National Institute of Biotic Stress Management, Baronda, Raipur; ICAR Research Complex for Goa, Old Goa; Central Salt and Marine Chemicals Research Institute, Bhavnagar, Gujarat; Academy of Scientific and Innovative Research, New Delhi; Indian Veterinary Research Institute, Izatnagar and Maharashtra Animal Science and Fishery University, Nagpur.

Cluster 13: It represents collaborations between authors from various departments of the Abdul Hakeem College, Melvisharam, Tamil Nadu, India.

Cluster 14: This cluster is based on the authorship trends among the National Taiwan Ocean University, Taiwan; University of Calcutta, Calcutta and Indira Gandhi Centre for Atomic Research, Kalpakkam, Tamil Nadu.
Cluster 15: The last cluster represents collaborations between authors from the Manonmaniam Sundaranar University, Tamil Nadu and the Sathyabama University, Jeppiaar Nagar, Chennai, Tamil Nadu.

\section{Conclusion}

Our study represented a snapshot on the scientific literature in fisheries and aquaculture published in journals indexed in Scopus database. It included quantitative assessment of various scientometric aspects of literary outcome on the subject. The results of the study brought forward that scientific literature on fisheries and aquaculture has almost continuously grown over the last decade. The authorship trends revealed the prevalence of high degree of research collaboration among scientists/ researchers working on this subject. India being the second and third largest producer of fisheries and aquaculture respectively, enjoyed research collaboration with countries from different parts of the world primarily led by the United States. Topics like oceanography/ hydrobiology, fish microbiology and health, fish haematology and carcass composition, fish growth, immunity and immune-stimulants, aquatic environment health and biodiversity and integrated system were the hot topics explored by researchers/scientists at both national and international level collaborations. The network visualization is expected to be useful to the scientific community in analysing the research trends in subject under study and further strengthening the research collaborations.

1. FAO, How to feed the world in 2050: insights from an expert meet of FAO. 2009, 1-35; http://www.fao.org/wsfs/forum2050/wsfsforum/en/.

2. World Bank, Fish to 2030: prospects for fisheries and aquaculture, 2014.

3. Subasinghe, R., Fishing for development, background paper for session 3: Green growth in fisheries and aquaculture, 2014; https://www.oecd.org/tad/events/Fishing-for-development-2014Session-3-GG-in-aquaculture.pdf.

4. Thorpe, A., Reid, C., Van Anrooy, R., Brugere, C. and Becker, D., Poverty reduction strategy papers and the fisheries sector: an opportunity forgone? J. Int. Dev., 2006, 18(4), 489-517.

5. Mohanty, B. P., Behera, B. K. and Sharma, A. P., Nutritional significance of small indigenous fishes in human health, 2010.

6. NFDB, About Indian fisheries, 2016; http://nfdb.gov.in/aboutindian-fisheries.htm.

7. Kumar, B. G. and Datta, K. K., Impact of science and technology on Indian fisheries sector, 2008; http://www.nistads.res.in/ indiasnt2008/t6rural/t6rur11.htm.

8. Poletto, V. C. and Faraco Junior, I. M., Bibliometric study of articles published in a Brazilian Journal of pediatric dentistry. Braz. Oral Res., 2010, 24(1), 83-88; http://www.scielo.br/ scielo.php?script $=$ sci_arttext\&pid $=$ S1806-832420100001000 14\& $\underline{\text { lng=en\&tlng=en. }}$.

9. Dias, J. D., Simões, N. R. and Bonecker, C. C., Net cages in fish farming: a scientometric analysis. Acta Limnol. Bras., 2012, 24, $12-17$. 
10. Sylvain, C., Canadian research activity in aquaculture: a bibliometric analysis. Scientometrics, 1993, 27(3), 295-316.

11. Santos, S. R. and Vianna, M., Scientometric analysis of the fisheries science for the species of cynoscion (sciaenidae: perciformes) from the Western Atlantic, with emphasis in the comparison of the North American and Brazilian fisheries catch data. Rev. Fish. Sci. Aquac., 2017, 26(1), 55-69; doi:10.1080/23308249.2017.1337078.

12. Aksnes, D. W. and Browman, H. I., An overview of global research effort in fisheries science. ICES J. Mar. Sci., 2016, 73, 1004-1011; https://doi.org/10.1093/icesjms/fsv248.

13. Natale, F., Fiore, G. and Hofherr, J., Mapping the research on aquaculture. A bibliometric analysis of aquaculture literature. Scientometrics, 2012, 90(3), 983-999.

14. Alves, D. C. and Minte-Vera, C. V., Scientometric analysis of freshwater fisheries in Brazil: repeating past errors? Rev. Fish Biol. Fish., 2013, 23(1), 113-126.

15. Singh, N., European journal of phycology: a bibliometric study. Int. J. Inf. Dissem. Technol., 6(3), 145-150.

16. Kumaresan, R., Ezhilrani, R., Vinitha, K. and Jayaraman, R., Indian research contributions in the aquaculture journal during 1972-2011: a scientometric study. Lib. Philos. Pract. (e-journal), 2014, 1185

17. Jayashree, B. and Arunachalam, S., Mapping fish research in India. Curr. Sci., 2010, 79(5), 613-620.

18. Arunachalam, S. and Jayashree, B., Fish science research in China: how does it compare with fish research in India? Scientometrics, 2001, 52(1), 13-28.
19. Rana, Madan, S. and Agarwal, S., Authorship trends in Indian wildlife and fisheries literature - a bibliometric study. Ann. Lib. Sci. Doc., 1994, 41(1), 13-18.

20. Ezhilrani, R., Surianarayanan, S. and Kanthimathi, S., Authorship pattern and collaborative research in aquaculture journals. SRELS J. Inf. Manage., 2006, 43(4), 391-398.

21. Ponnudurai, R. and Shabu, Research productivity on fish and fishing industry in India. Int. J. Pharm. Biol. Arch., 2013, 4(4), 747750 .

22. Chaman Sab, M., Dharani Kumar, P. and Biradar, B. S., Scientometric study of the research performance on fishery: the Indian perspective. J. Adv. Lib. Inf. Sci., 2016, 5(2), 337-341.

23. Van Eck, N. J. and Waltman, L., Visualizing bibliometric networks. In Measuring Scholarly Impact: Methods and Practice (eds Ding, Y., Rousseau, R. and Wolfram, D.), Springer, 2014, pp. 285-320.

ACKNOWLEDGEMENTS. We express thanks to the Librarian, and the Dean, College of Fisheries, Guru Angad Dev Veterinary and Animal Sciences University (GADVASU), Ludhiana for the necessary support. The help of Mr Abhishek Srivastava, Assistant Professor, College of Fisheries, GADVASU is also acknowledged.

Received 15 May 2018; revised accepted 20 May 2019

doi: $10.18520 / \mathrm{cs} / \mathrm{v} 117 / \mathrm{i} 3 / 382-389$ 